\title{
Potential effect of microwaved vermicast on dahlia plant growth and flower production
}

\begin{abstract}
Enhancement of natural growing medium amendments with microwave irradiation has been demonstrated but has received less research attention. A greenhouse experiment was carried out to determine the effect of microwaved vermicast on dahlia (Dahlia pinnata 'Cobequid Celestial Star') plant growth and flower production. Fresh, moist vermicast was treated with microwave irradiation power levels $100 \mathrm{~W}, 200 \mathrm{~W}, 400 \mathrm{~W}$ and $800 \mathrm{~W}$ with non-microwaved vermicast as the control $(0 \mathrm{~W})$. The temperature of the microwaved vermicast increased from $35^{\circ} \mathrm{C}$ at $100 \mathrm{~W}$ to $80^{\circ} \mathrm{C}$ at $400 \mathrm{~W}$, but dropped to $70^{\circ} \mathrm{C}$ at $800 \mathrm{~W}$. The density of bacteria colonies was high in treatments $0 \mathrm{~W}, 100 \mathrm{~W}$ and $200 \mathrm{~W}$, and the least in treatment $400 \mathrm{~W}$ while treatment $800 \mathrm{~W}$ did not support bacteria growth. Total nitrogen content did not change much but leaf tissue phosphate content increased from $0.70 \%(100$ $\mathrm{W})$ to $0.83 \%(800 \mathrm{~W})$. Leaf tissue chlorophyll content was increased by treatment $400 \mathrm{~W}$ followed by the FV while anthocyanin content consistently increased with an increase in power output level. Microwave irradiation increased total plant and tuberous roots fresh weights. Those treatments $\geq 200 \mathrm{~W}$ had the greatest positive impact on total number of floral organs and longevity of flowers as compared to the $0 \mathrm{~W}$ and the $100 \mathrm{~W}$ treatments. Overall, it was demonstrated that microwave irradiation at $400 \mathrm{~W}$ improve vermicast chemical properties and enhance dahlia plant growth and flower production. Further study on microbial structure will be necessary.
\end{abstract}

Keywords: dahlia, microwave irradiation, vermicompost, organic amendment
Volume 3 Issue 4 - 2019

\author{
Shixin Cai, Adedayo Leke-Aladekoba, Scott \\ Veitch, Lord Abbey \\ Department of Plant, Food and Environmental Sciences, Faculty \\ of Agriculture, Dalhousie University, Canada
}

\begin{abstract}
Correspondence: Lord Abbey, Faculty of Agriculture, Department of Plant, Food and Environmental Sciences, Dalhousie University, 50 Pictou Road, Truro B2N 5E3, Nova Scotia, Canada, Email loab07@gmail.com , LAbbey@Dal.Ca
\end{abstract}

Received: August 12,2019 | Published: August 19, 2019

\section{Introduction}

Dahlia (Dahlia pinnata), a member of the Asteraceae family, is a semi-hardy, erect and herbaceous perennial plant with tuberous root system. Dahlia plants are well-known for their distinctive culinary, socio-cultural, environment and economic benefits. ${ }^{1}$ Globally, there are approximately 30 distinct perennial species of dahlia that are valued for their wide range of petal colors, floral forms and sizes, and edible quality of their tuberous roots. ${ }^{2,3}$ The value of these functional characteristic and plant growth and yield performance are dependent on genotype, environmental and edaphic factors.

Synthetic chemical fertilizers are extensively used by dahlia growers to enhance plant growth, yield and flower characteristics. ${ }^{4}$ However, recent trend in the global floriculture industry indicated an upsurge of interest in organically produced ornamental plants and flowers due to perceived agro-ecological, environmental, health and social benefits. As a result, many different natural amendments such as compost, vermicast, seafood and seaweed extracts are incorporated in growing medium substrates and in some cases, liquid formulations are used as foliar applications or soil drench in organic flower production systems. Vermicast is the resultant pure worm excreta obtained during vermicomposting process by worms such as the Red Wiggler worm (Eisenia fetida). This bioproduct is rich in various organic carbon compounds, enzymes, phytohormones, mineral nutrients and beneficial microorganisms. ${ }^{5}$ Most of these nutrients are in forms that the active ingredients are readily available for plant use. Despite these evidences, not much research has been performed to determine vermicast effect on dahlia plant vegetative growth and flower production.

Dehydration of vermicast to improve storage ability, handling and application efficiency is on the rise. ${ }^{6}$ The dehydration process can lead to densification of nutrients in vermicast that can potentially improve nutrient availability and nutrients use-efficiency in plants. Microwave is a smart technology but rarely used in agriculture. A study by Abbey et al. ${ }^{7}$ showed that microwave irradiation of vermicast at $400 \mathrm{~W}$ for 5 mins increased the density of nutrients, altered microbial population in the growing medium in addition to increasing growth of potted Chinese cabbage (Brassica rapa subsp. chinensis) plants. As a follow up, Yu et al. ${ }^{8}$ was able to increase the nutrient density of municipal solid waste compost tea, which ultimately enhanced plant growth and chemical composition of Plectranthus amboinicus. All these studies demonstrated that microwave irradiation can densify chemicals in natural growing medium amendments with positive response from different plant species.

Vermicast, like food matrix, contains polar molecules such as water with random orientation. Upon passing of microwave electromagnetic field, the polarity alternates very rapidly leading to friction and localized internal superheating, ${ }^{9}$ which may be the cause of alteration in vermicast nutrient density and microbial population in the study by Abbey et al. ${ }^{7}$ Therefore, it was postulated that microwave irradiation at increasing power level will improve vermicast quality indices that will enhance dahlia plant vegetative growth and flower production. The objectives of the study were to determine the effects of variation in microwave irradiation power output level on the densities of microorganisms and mineral nutrients, and to assess the effects of the microwaved vermicast on dahlia 'Cobequid Celestial Star' plant growth, flower production and yield of tuberous roots.

\section{Materials and methods}

\section{Location and materials}

Laboratory and greenhouse experiments were performed at the Department of Plant, Food, and Environmental Sciences between spring (April) and summer (August). The greenhouse temperature 
during plant growth ranged between $20 \mathrm{o}$ to $25^{\circ} \mathrm{C}$ in the day and $10 \mathrm{o}$ to $15^{\circ} \mathrm{C}$ at night, and a mean relative humidity of $72 \%$. Supplementary lighting was provided by a $600 \mathrm{~W}$ HS2000 high pressure sodium lamp with NAH600.579 ballast (P.L. Light Systems, Beamsville, ON, Canada) at 12-hr day/night cycle in the months of April to May after which ambient light conditions improved from June. Tuberous roots of dahlia (Dahlia pinnata 'Cobequid Celestial Star') were obtained from Nova Scotia Dahlia Society, Canada. Fresh, moist vermicast was purchased from Cathy's Crawlers (Cathy's Crawlers Composters, Niagara, Ontario, Canada). Promix-BX ${ }^{\mathrm{TM}}$ potting medium (Premier Horticulture Inc., Quakertown, PA, USA) was purchased from Halifax Seeds, Canada.

\section{Sample preparation and microwave irradiation}

One-hundred (100)-g portion of the fresh, moist vermicast was put in a microwavable pyrex glass bowl and individually irradiated at four different microwave power output levels: (i) $0 \mathrm{~W}$ (control, no microwave), (ii) $100 \mathrm{~W}$, (iii) $200 \mathrm{~W}$, (iv) $400 \mathrm{~W}$ and (v) $800 \mathrm{~W}$ for 5 min. A General Electric microwave oven (model JES1295STC01; MABE Canada Inc., Mississauga, Ontario, Canada) was used to irradiate the vermicast in the laboratory as described by Abbey et al. ${ }^{7}$ They recommended microwaving vermicast at $400 \mathrm{~W}$ for the best outcome and therefore, it was used as the target power output level for the present work. Heat pulsation was performed to avoid heat build-up by stopping the microwave equipment at $2.5 \mathrm{mins}$ to stir the vermicast, and then restarted for another $2.5 \mathrm{~min}$. This process ensured even distribution of heat within the vermicast as described by Hendricks and Pascoe. ${ }^{10}$

\section{Chemical analysis}

One hundred (100) $\mathrm{ml}$ of distilled water was added to each 100$\mathrm{g}$ portion of each microwaved vermicast treatment and also the control, and vortexed for 15 mins using Isotemp stirring plate (model LT1892X1; Thermo Fisher Scientific Inc., Markham, ON, Canada). The mixture was allowed to stand for $1 \mathrm{hr}$ after vortex to settle prior to determining electric conductivity (EC), potential hydrogen concentration $(\mathrm{pH})$, total dissolved solids (TDS) and salinity of the liquefied vermicast using Oakton multi-parameter (model PCTesterTM 35; Eutech Instruments Pte Ltd, Illinois, USA). All determinations were done in triplicates. Another set of 300-g sample of each microwaved vermicast and the control fresh, moist vermicast were sent to the Nova Scotia Agriculture Laboratory Services, Truro for macro- and micro-nutrients analyses.

\section{Determination of microbial density}

A LaMotte BioPaddles ${ }^{\circledR}$ Tryptic soy agar (model 5552; LaMotte Company, Washington, USA) was used to determine the density of aerobic and anaerobic bacteria of the different microwaved vermicast treatments. The microbial density assessment was done by adding 95 $\mathrm{ml}$ of distilled water to each 5-g sample of the vermicast treatment, and vortexed for $15 \mathrm{~min}$. The individual mixtures stood for $1 \mathrm{hr}$ to settle before separation of the supernatant from the solid residue at the bottom. The BioPaddles ${ }^{\circledR}$ was dipped in $40 \mathrm{ml}$ of the supernatant contained in individually labelled vials for $30 \mathrm{~s}$ before removing to allow free liquefied compost to drain off the agar. The inoculated BioPaddles ${ }^{\circledR}$ were individually placed in their respective empty vials and incubated at $35^{\circ} \mathrm{C}$ in a Z-Sciences Growth chamber (model LHT2103D; Z-Sciences Corporation, Quebec, Canada) per manufacturer's instruction. Visual observation was performed on the densities of the microbial colonies formed on the BioPaddles ${ }^{\circledR}$ after $48 \mathrm{hr}$. The manufacturer's guideline was used to estimate the density of each colony.

\section{Pot filling, planting and medium amendment}

Dahlia 'Cobequid Celestial Star' tubers were pre-sprouted in perlites contained in flat trays under mist conditions for four months before transplanting into a 61 nursery pots filled with $3.2 \mathrm{~kg}$ of moistened Pro-Mix BX TM soilless potting medium. One hundred (100) $\mathrm{g}$ of fresh, moist vermicast without microwave $(0 \mathrm{~W})$ or microwaved at the four different power levels (i.e. $100 \mathrm{~W}, 200 \mathrm{~W}, 400$ $\mathrm{W}$ and $800 \mathrm{~W}$ ) was incorporated in the individual potted Pro-Mix BX TM soilless medium. One pre-sprouted dahlia tuber was transplanted into each pot before placing on the greenhouse bench. All plants were watered as needed. A second round of application of vermicast treatments was performed as top up at eight weeks after transplanting. Plants were re-arranged on the bench periodically to offset any bias due to variations in microclimate in the greenhouse.

\section{Experimental design and data collection}

The experimental design was completely randomized design with eight potted-plant samples per treatment. Data were collected on four potted plants per treatment. Data collected on plant growth and yield components included leaf greenness i.e. chlorophyll content using SPAD chlorophyll meter (model 502; Spectrum Technologies Inc., Aurora, Illinois, USA) and anthocyanin content using Anthocyanin meter (model ACM-200; Hoskin Scientific, Vancouver, Canada). Both chlorophyll and anthocyanin contents were recorded from the third or fourth youngest leaf on the main stem per plant. Stem diameter was measured at $15-\mathrm{cm}$ height above the collar using a pair of Mastercraft electronic calipers (Masstores (Pty) Ltd., Johannesburg, South Africa) at harvest; and the total plant fresh weight was determined by weighing the entire plant including developing tuberous roots at final harvest using Highland electronic balance (model HCB602H; ADAM Equipment Inc., Oxford, UK). The tuberous roots were also severed from the shoot and the fresh weights were recorded. The dry weights of the tuberous roots were determined by the oven-drying method at $65 \pm 2^{\circ} \mathrm{C}$ until constant weight was achieved in approximately $72 \mathrm{hr}$ using Cole-Parmer mechanical convection oven dryer (model 510010; Cole-Parmer Co., Vernon Hills, Illinois). The total number of flowers and flower buds were counted every two weeks from the 9thto the 15 th-week after transplanting.

\section{Statistical analyses}

Data collected were subjected to one-way analysis of variance (ANOVA) using Minitab version 17.3 (Minitab Inc., State College, PA, USA). Fisher's least significant difference (LSD) method was used to separate treatment means when the ANOVA indicated a significant difference at $\mathrm{P} \leq 0.05$. Graphs were plotted using Microsoft Excel.

\section{Results and discussion}

The temperature of the vermicast was increased from $21^{\circ} \mathrm{C}$ to $80^{\circ} \mathrm{C}$ as the microwave irradiation (MWI) power output level was increased from $0 \mathrm{~W}$ to $400 \mathrm{~W}$ (Table 1). Subsequently, the temperature of the vermicast was reduced by $10^{\circ} \mathrm{C}$ when the power output level was increased from 400 to $800 \mathrm{~W}$. This observation agreed with the explanation on microwave electromagnetic energy output by Carreto et al. (2015). The loss of moisture at higher microwave power level 
led to a reduction in heat retention in the vermicast granules (Motevali et al; Abbey et al.).?

Table I Microwave irradiation power and energy output levels for the treatment of vermicast, and the corresponding temperature recorded immediately after 5 mins of exposure

\begin{tabular}{lll}
\hline $\begin{array}{l}\text { Power output } \\
\text { level (W) }\end{array}$ & $\begin{array}{l}\text { Output } \\
\text { energy }(\%)\end{array}$ & $\begin{array}{l}\text { Vermicast } \\
\text { temperature }\left({ }^{\circ} \mathbf{C}\right)\end{array}$ \\
\hline 0 & 0 & 21 \\
100 & 10 & 35 \\
200 & 20 & 60 \\
400 & 40 & 80 \\
800 & 80 & 70 \\
\hline
\end{tabular}

They explained that principle of operation of microwaves is based on activation and collision of water molecules in an exposed material. Thus at $800 \mathrm{~W}$, the high frequency of the microwave electromagnetic radiation increased thermal heat energy that greatly dehydrated the vermicast.

Variation in microwave power output level influenced the density of bacteria populations in the vermicast (data not presented). Bacteria densities in the 0,100 and $200 \mathrm{~W}$ treatments were greater than those in treatments 400 and $800 \mathrm{~W}$. According to the manufacturer's bioassay manual for BioPaddles ${ }^{\circledR}$ Tryptic soy agar, the estimated bacteria counts were approximately 104 for the $0 \mathrm{~W}$ and the $100 \mathrm{~W}$ treatments as compared to approximately 106 for the $200 \mathrm{~W}$ treatment. This suggested that the low thermal effects of the $100 \mathrm{~W}$ treatment did not influence bacteria population in the vermicast. On the other hand, the $200 \mathrm{~W}$ treatment seemed to have stimulated the proliferation of bacteria colonies in the vermicast. It is possible that treatment 200 $\mathrm{W}$ led to thermal hydrolysis of chemical compounds that stimulated the proliferation of bacteria. Treatments $400 \mathrm{~W}$ and $800 \mathrm{~W}$ greatly reduced bacteria density in the vermicast to a total count of $<103$ and almost negligible, respectively. These findings agree with earlier report, which demonstrated that exposure of compost to microwave irradiation can partially damage microbial cells or completely kill microorganisms to render the medium sterile (Song et al, Carreto et al.). ${ }^{11}$

There was a slight decline in total nitrogen $(\mathrm{N})$ content in the 100 $\mathrm{W}$ treated vermicast while phosphate $\left(\mathrm{P}_{2} \mathrm{O}_{5}\right)$ content slightly increased (Table 2). Potassium $(\mathrm{K})$, boron $(\mathrm{B})$ and copper $(\mathrm{Cu})$ contents in the treated vermicast did not change.

Zinc ( $\mathrm{Zn})$ content in the vermicast was reduced by increasing microwave irradiation power output level from $100 \mathrm{~W}$ to $800 \mathrm{~W}$. Comparatively, treatment $0 \mathrm{~W}$ recorded the highest Fe and $\mathrm{Zn}$ contents while treatment $200 \mathrm{~W}$ recorded the least. The Fe content rose when the microwave power output level increased from $400 \mathrm{~W}$ to $800 \mathrm{~W}$. Treatment $200 \mathrm{~W}$ increased manganese (Mn) content while all the other treatments recorded low but similar amount of $\mathrm{Mn}$ in their respective vermicast. Previous researchers attributed increased nutrient density in microwaved materials to microbial cell wall damage and leakage of cell materials (Song et al. 2012; Carreto et al.; Abbey et al). ${ }^{11,7}$ It can also be attributed to loss of moisture and increased overall particle density in association with increased chemical concentration in the microwaved material, which could explain the observed increments in overall nutrient density in the microwaved vermicast.

Table 2 Nutrients content of vermicast exposed to different microwave power output levels

\begin{tabular}{lllllllll}
\hline Power output (W) & N (\%) & P2O5 (\%) & K (\%) & B (mg/l) & Fe (mg/l) & Zn (mg/l) & Mn (mg/l) & Cu (mg/l) \\
\hline 0 & 1.56 & 0.7 & 0.16 & 20.41 & 4441.6 & $139.8 \mid$ & 269.58 & 15.44 \\
100 & 1.64 & 0.7 & 0.16 & 21.31 & 4295.87 & 137.26 & 267.28 \\
200 & 1.61 & 0.72 & 0.16 & 20.41 & 3980.97 & 133.52 & 289.25 & 16.05 \\
400 & 1.54 & 0.73 & 0.15 & 19.32 & 4350.86 & 136.81 & 261.82 & 15.07 \\
800 & 1.57 & 0.83 & 0.16 & 20.61 & 4097.31 & 136.77 & 265.83 & 16.19 \\
\hline
\end{tabular}

Chlorophyll content of dahlia plants applied with treatment 400 W was significantly $(\mathrm{P}<0.05)$ the highest (Figure 1$)$. Treatments 100 $\mathrm{W}, 200 \mathrm{~W}$ and $800 \mathrm{~W}$ had low and similar effects on dahlia plant chlorophyll content. It is generally reported that when ambient temperature and light conditions are suitable for the synthesis of chlorophyll the lack of adequate nutrients typically $\mathrm{N}$, sulphur (S), $\mathrm{Fe}, \mathrm{Mn}$ and $\mathrm{Cu}$ can cause chlorosis and reduce photosynthesis and plant growth. ${ }^{12}$ Therefore, the variations in dahlia plant leaf tissue chlorophyll content will have differential impact on photosynthetic capacity and plant health status as reported by Ling et al. ${ }^{13}$ Although the individual nutrients were low in $400 \mathrm{~W}$ vermicast (Table 2) dahlia plants treated with the $400 \mathrm{~W}$ microwaved vermicast had the highest chlorophyll content as compared to the other treatments (Figure 1). This finding suggested that the nutrients in the $400 \mathrm{~W}$ treated vermicast were more balanced and more bioavailable for plant use as compared to the other treatments. Furthermore, an increase in microwave irradiation power output level from $100 \mathrm{~W}$ to 800 $\mathrm{W}$ consistently increased anthocyanin content of the dahlia plants i.e. $0 \mathrm{~W}<100 \mathrm{~W}<200 \mathrm{~W}<400 \mathrm{~W}<800 \mathrm{~W}$ (Figure 1). Again, the 400 $\mathrm{W}$ treatment recorded the highest anthocyanin content of the plant tissues, which was not significantly $(\mathrm{P}>0.05)$ different from the 800 W treatment. According to Oberbauen and Starr (2002), anthocyanin accumulation increases leaf tissue flavonoid concentration and enhances photosynthesis, which can be beneficial to dahlia plants treated with the $400 \mathrm{~W}$ microwaved vermicast,

Total plant fresh weight (i.e. flowers, stems, leaves and tuberous roots) of dahlia 'Cobequid Celestial Star' at final harvest was significantly $(\mathrm{P}<0.05)$ increased by treatments 200 and $400 \mathrm{~W}$, but was significantly $(\mathrm{P}<0.05)$ reduced by treatment $800 \mathrm{~W}$ (Figure 2$)$. Total plant fresh weight was lower and similar in plants that were grown in treatments 0 and $100 \mathrm{~W}$. Treatment $0 \mathrm{~W}$ gave the highest tuberous roots fresh weight as compared to all the other treatments (Figure 2). Also, there was a general trend of increasing tuberous roots fresh weight as microwave power output level increased from $100 \mathrm{~W}$ to 800 W. It is worth noting that dahlia plants that received the $400 \mathrm{~W}$ treated vermicast consistently had the highest incremental impact. These 
findings confirmed earlier observations made recently by Abbey et al. ${ }^{7}$ and $\mathrm{Yu}$ et al. ${ }^{8}$ The former reported that $400 \mathrm{~W}$ microwaved vermicast increased plant growth as compared to power output levels (i.e. $<400$ $\mathrm{W}$ or $>400 \mathrm{~W}$ ) studied. The increase in vegetative growth following treatment $400 \mathrm{~W}$ in the present study can be attributed to increased nutrients bioavailability in addition to the high anthocyanin and the chlorophyll contents as shown in Figure 1.

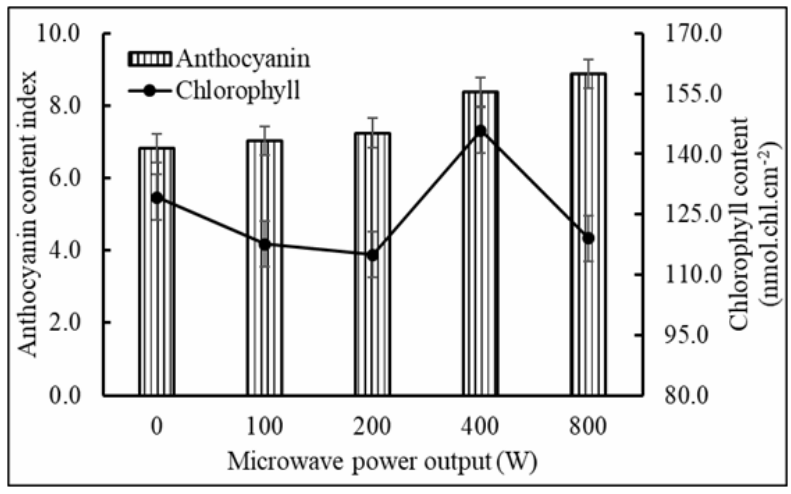

Figure I Leaf chlorophyll and anthocyanin contents of dahlia 'Cobequid Celestial Star' treated with microwaved vermicast. Vertical bars are standard errors.

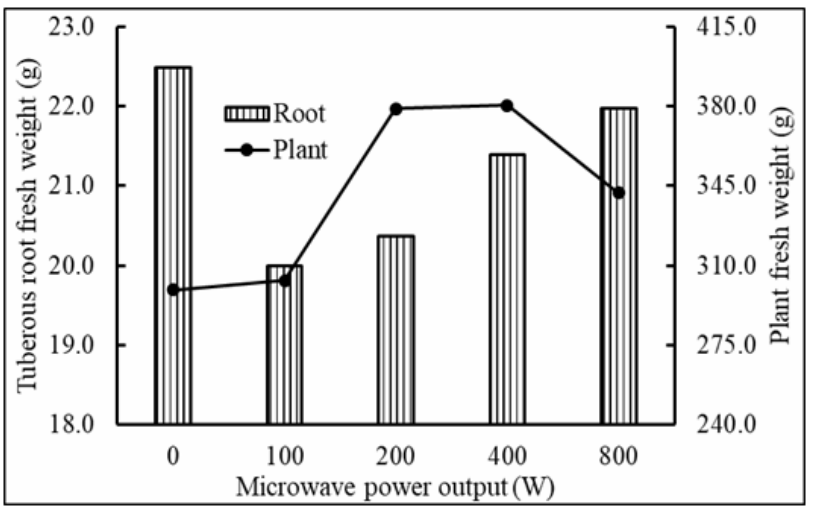

Figure 2 Plant and tuberous root fresh weights of dahlia 'Cobequid Celestial Star' plants treated with microwaved vermicast.Vertical bars are standard errors.

The total number of floral organs (i.e. fully or partially opened flowers and flower buds) were differentially affected by the variations microwave treatments of the vermicast (Figure 3). For instance, it was found that vermicast exposed to $\geq 200 \mathrm{~W}$ microwave irradiation had the greatest impact on total number and longevity of dahlia floral organs as compared to the $0 \mathrm{~W}$ and the $100 \mathrm{~W}$ treatments. There was a sharp rise in flower production on all the dahlia plants at the end of week 13 except those plants that were treated with the $100 \mathrm{~W}$ and the $400 \mathrm{~W}$ microwaved vermicast. Particularly, treatment $800 \mathrm{~W}$ produced the most flowers by week 13 followed by the $200 \mathrm{~W}$ treatment, but there was a sharp drop in flower production in the former by week 15.

Termination of new floral organ production and increased rate of senescence in matured flowers can be the main reasons for the significant drop in the total number of floral organs on plants grown in the $0 \mathrm{~W}$ and the $800 \mathrm{~W}$. Further research is underway to explain this observation on matured dahlia plants. Previous researchers explained that higher growing medium $\mathrm{P}$ content can increase production of dahlia flowers, extend the blooming period and flower size. ${ }^{4,15}$ However, these were not obvious in the present study, which can be attributed to the early termination of the experiment before tuberous roots development were completed.

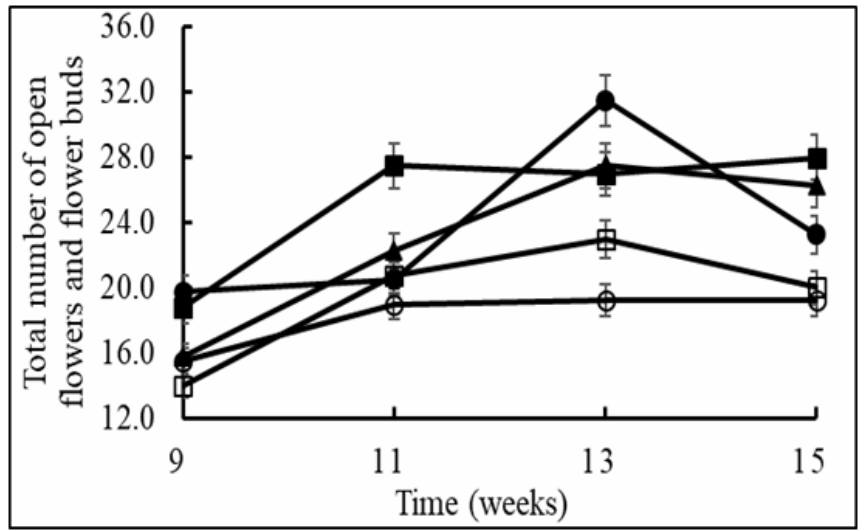

Figure 3 Total number of opened flowers and flower buds of dahlia 'Cobequid Celestial Star' plants treated with microwaved vermicast. Vertical bars are standard errors. 0W, open square; I00W, open circle; 200 $\mathrm{W}$, closed triangle; $400 \mathrm{~W}$, closed square; and $800 \mathrm{~W}$, closed circle.

In conclusion, the present study is the first of its kind, and the preliminary findings suggested microwave irradiation alteration of vermicast bio-physicochemical properties and enhancement effect on dahlia 'Cobequid Celestial Star' plant growth and flower production. The results agree with previous study, which suggested that microwave irradiation at power output level $400 \mathrm{~W}$ can have significant thermal effect on vermicast. Microwave irradiation at $400 \mathrm{~W}$ and $800 \mathrm{~W}$ disrupted microbial cells and thereby, reduced microbial density in the vermicast. However, treatment $400 \mathrm{~W}$ consistently provided the best overall condition to support dahlia plant growth and flower production. It seemed treatment $400 \mathrm{~W}$ provided a favorable nutrient balance and made nutrients more bioavailable leading to improved plant health and growth. The higher the microwave power output level, the higher the flower production, which was more consistent with the $400 \mathrm{~W}$ treatment. Further investigation is currently underway to provide detail explanation of some of the findings before reaching firm conclusions for recommendations on dahlia plant response to microwave irradiated vermicast.

\section{Funding}

The research did not receive any specific grant from funding agencies in the public, commercial, or not-for-profit sectors. However, I would like to thank my department for providing partial funding for student project.

\section{Acknowledgement}

The authors wish to thank Dr. Sam Asiedu, Dr. Nancy McLean, and Ms. Krista MacLeod for their assistance during this study.

\section{Conflicts of interest}

The authors declare that there is no conflict of interest.

\section{References}

1. Park JH, Choi IY, Park MJ, et al. First report of choanephora flower blight on dahlia pinnata caused by choanephora cucurbitarum in Korea. Plant Dis. 2015;100(2):534. 
2. Yan ST, Li XD, Li WD, et al. Photosynthesis and chlorophyll fluorescence response to low sink demand of tubers and roots in Dahlia pinnata source leaves. Biologia Plantarum. 2011;55(1):8-89.

3. Ciobanu I, Cantor M, Buta E, et al. Influence of cultivar and planting material on soluble dry matter content of dahlia tuberous roots. Bull. UASVM Hort. 2016;73(2):135-140.

4. Younis A, Riaz A, Khosa SS, et al. Effect of foliar application of macro and micronutrients on growth and flowering of Gerbera jamesonii $\mathrm{L}$. American-Eurasian J Agric Env Sci. 2011;11:736-757.

5. Chattopadhyay A. Effect of vermiwash and vermicompost on an ornamental flower. Zinnia sp. J Hort. 2014;1-4.

6. Abbey L, Rao SA, Hodgins LN, et al. Drying and rehydration of vermicast do not affect nutrient bioavailability and seedling growth. Am J Plant Nutr Fert Technol. 2013;3(1):12-21.

7. Abbey L, Udenigwe C, Mohan A, et al. Microwave irradiation effects on vermicast potency, and plant growth and antioxidant activity in seedlings of Chinese cabbage (Brassica rapa subsp. pekinensis). J Rad Res Appl Sci. 2017;10:110-116.

8. Yu H, Iheshiulo EMA, Gunupuru LR, et al. Microwave power level and exposure time alteration of compost tea efficacy, and growth of Plectranthus amboinicus. Hort Intl J. 2019;3(4):179-184.
9. Mandal V, Mohan Y, Hemalatha S. Microwave assisted extraction of curcumin by sample-solvent dual heating mechanism using Taguchi L9 orthogonal design. J Pharm Biomed Anal. 2008;46:322-327.

10. Hendricks CW, Pascoe N. Soil microbial biomass estimates using 2450 MHz microwave irradiation. Plant and Soil. 1988;110(1):39-47.

11. Song ZX, Wang ZY, Wu LY, et al. Effect of microwave irradiation pretreatment of cow dung compost on bio-hydrogen process from corn stalk by dark fermentation. Intl J Hydr. Energy. 2012;37(8), 6554-6561.

12. Havlin J. Soil fertility and fertilizers: An introduction to nutrient management. 7th ed. Pearson Prentice Hall. Upper Saddle River NJ; 2005 .

13. Ling Q, Huang W, Jarvis P. Use of a SPAD-502 meter to measure leaf chlorophyll concentration in Arabidopsis thaliana. Photosyn Res. 2011;107:209-214.

14. Oberbauen SF, Starr G. The role of anthocyanins for photosynthesis of Alaskan arctic evergreens during snowmelt. Adv Bot Res. 2002;37:129 145

15. Tariq U, Rehman SU, Khan MA, et al. Agricultural and municipal waste as potting media components for the growth and flowering of Dahlia hortensis 'Figaro'. Turk J Bot. 2012;36(4):378-385. 